\title{
Understanding safety culture by visualization of scenarios - development and evaluation of an interactive prototype
}

\author{
Mikael Blomé ${ }^{\mathrm{a}, *}$ and Åsa $\mathrm{Ek}^{\mathrm{a}}$ \\ ${ }^{a}$ Ergonomics and Aerosol Technology, Department of Design Sciences, Faculty of Engineering, Lund University, \\ P.O. Box 118, SE-22100 Lund, Sweden
}

\begin{abstract}
To be able to disseminate knowledge about maritime safety culture and safety management to different actors in the Swedish maritime sector, a preliminary pedagogical concept was developed and evaluated. As a first user group, students at upper secondary maritime schools were chosen and the pedagogical concept was adapted for this group. The concept includes an interactive prototype and a teacher's guide and is based on a model for experience-based learning which connects theory and practice by a cyclic approach. The concept was tested in a classroom setting including interaction with the students and a follow-up one week later. A preliminary evaluation of the results shows a very positive response among the students as well as the lecturers. The educational material was successful in immediately creating a relevant discussion about safety culture, and one week later, students could remember many of the safety scenarios included in the pedagogical concept.
\end{abstract}

Keywords: Learning tool, maritime safety, visualization, interactive prototype

\section{Introduction}

A Swedish maritime safety project (MARSAF) was carried out with the aim to yield new knowledge for increased safety at sea. It focused on human and organizational factors, safety management and safety culture [1-3]. At the end of the project, discussions were held with representatives from the maritime sector, including shipping companies, vessel crews, the Maritime Department at the Swedish Transport Agency and trade unions. They all emphasized the need for dissemination of the results and knowledge gained in the project to the sector. Positive attitudes towards safety and a good safety culture across the sector are a foundation for good safety at sea. The dissemination of safety knowledge must reach actors at all levels in the sector for increased safety awareness. The attitudes and behaviours of individuals and organizations with respect to safety have important implications for the actual risk for maritime accidents, and understanding of these issues needs to be rooted early in a seaman's education.

Thus, the aim of this study was to develop and evaluate a pedagogical concept including an interactive prototype to educate students at upper secondary maritime schools in the area of safety culture on board vessels and continuous safety improvement.

The pedagogical concept was developed based on earlier research on methods for dissemination of knowledge [4]. The method is based on a model for experience-based learning, which connects theory and practice by a cyclic approach.

\section{Materials and methods}

\subsection{Development of a preliminary pedagogical concept}

A pedagogical concept was developed by the authors where knowledge about safety and behaviour at sea were visualized in an interactive prototype with

\footnotetext{
Corresponding author. E-mail: Mikael.Blome@design.lth.se
} 
an accompanying teacher's guide. The knowledge was structured in six key areas important for safety and nine important aspects of safety culture. Each area and aspect was then visualized according to principles from earlier and similar visualization studies $[4,5,6]$ with combinations of pictures, animated scenarios and models with text and hyperlinks.

The prototype was accompanied by a draft of a teacher's guide explaining the material in words and images and the recommended usage of the prototype in learning situations.

The pedagogical concept with the interactive prototype and teacher's guide was presented and discussed with two lecturers at an upper secondary maritime school in Sweden. Based on these discussions some revisions were made, such as simplifying some formulations to fit the students at this level. It was decided to test and evaluate the concept with one of their classes of students.

\subsection{Procedure for testing the concept}

The interactive prototype was presented and was viewed by navigating within the prototype and the demonstrated by the authors to a group of 20 students on a scheduled occasion. The educational material content was discussed with the students in the classroom. The authors revisited the students after one week and evaluated the concept with questionnaires and discussions. The evaluation concerned if the students liked the pedagogical concept as such, but also learning aspects such as if they could remember any of the safety scenarios in the concept.

\section{Results}

\subsection{The interactive prototype}

The information and knowledge of safety culture were visualized with scenarios, illustrations and animations, see Figure 1. The starting page introduces and generally defines the safety culture concept and provides two paths into the educational material either via the six key safety areas, or via the nine aspects of safety culture.

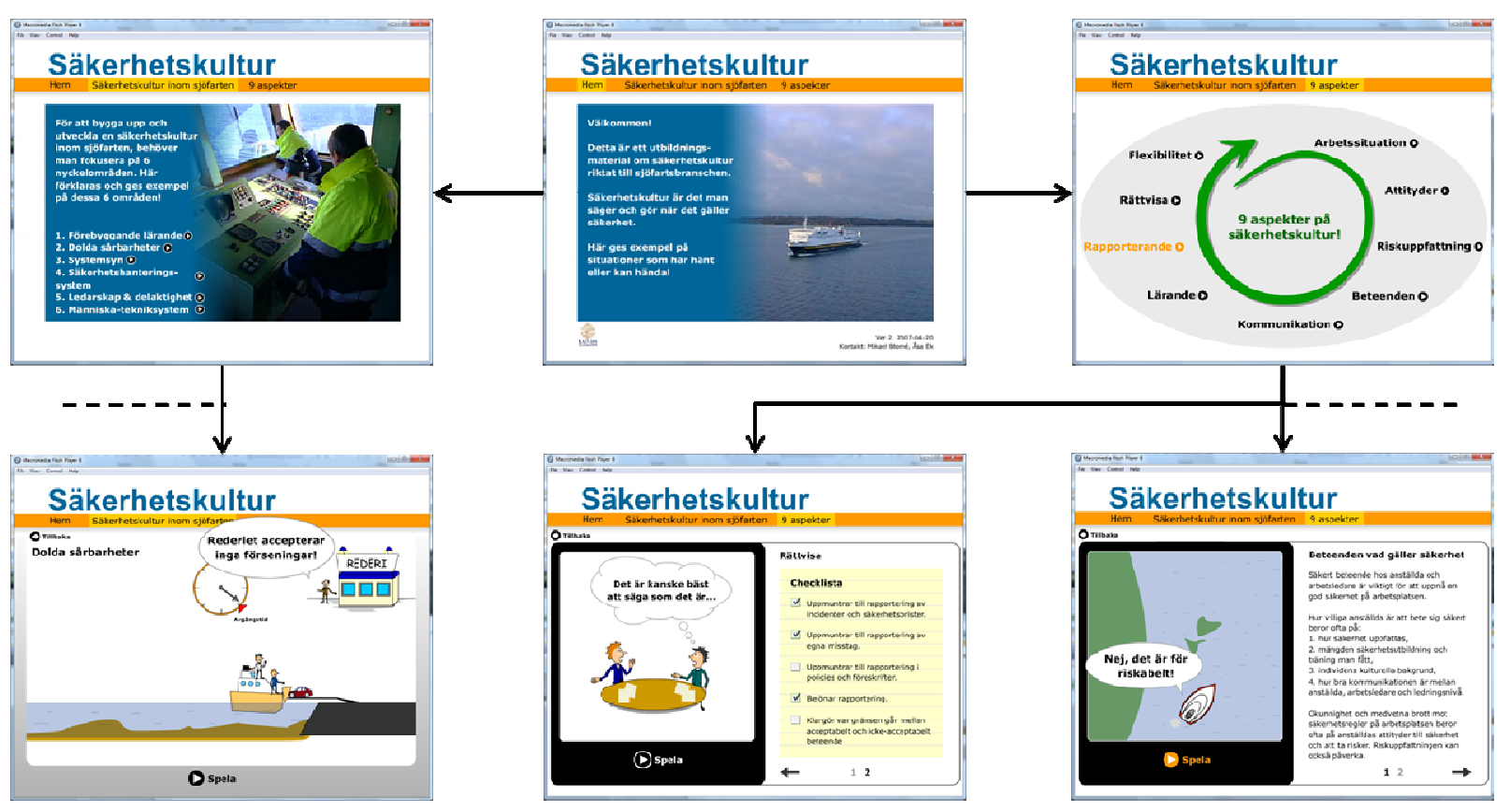

Fig.1. Six screenshots of the interactive prototype showing paths to specific scenarios and specific aspects of safety culture. 
The six key safety areas described in the material are proactive learning, latent conditions, a system's view to safety, safety management system, leadership and participation, and man-technology system. The nine aspects of safety culture described in the material are work situation, attitudes towards safety, risk perception, safety-related behaviours, communication, learning, reporting, justness, and flexibility.

\subsection{Preliminary outcome}

A preliminary evaluation of the results shows a very positive response among the students as well as the lecturers. The educational material was successful in immediately creating a relevant discussion about safety culture and the students could easily connect the presented scenarios to their own knowledge and safety experiences gained during their practices onboard vessels. The student group could, on the whole, remember and describe all scenarios a week after the presentation of the material. The participating lecturer was also very positive and considered himself able to execute the concept with support of the teacher's guide.

\section{Discussion}

This paper presented a preliminary pedagogical concept for increased maritime safety awareness with the purpose of educating students at upper secondary maritime schools.

The educational material can be used freestanding or as part of a larger course. The material should be used as a starting point for introducing important terms and concepts related to safety management. After the introduction the participants can utilize the terms and concepts in order to explain and analyse their own experiences. With that, a pedagogical model for experience-based learning is applied which couples theory and practice in a cyclic manner.
The results were positive in the first testing of the concept in a group of maritime students. To reach a deeper anchorage in the educational processes in the maritime school, several suggestions concerning the use and integration of the concept into the educational programme will be forwarded and discussed with the teachers.

As the preliminary results from the first testing of the concept were positive, the authors believe the concept can also be adapted and developed for other users in the maritime sector, for example, vessel crews.

\section{Acknowledgement}

This project was supported by grants from the Swedish Mercantile Marine Foundation.

\section{References}

[1] A.. Ek and R. Akselsson, Safety culture on board six Swedish passenger ships, Maritime Policy \& Management 32 (2005), 159-176.

[2] M.Q. Mejia Jr., P.K. Mukherjee and R. Akselsson, The ISM Code in the context of Swedish port state control statistics, in: Ocean Yearbook 21, A. Chircop, S. Coffen-Smout, M. McConnell, eds., Brill, The Netherlands, 2007, 405-426.

[3] G. Jense, ISM- koden om säkerhetsorganisation, säkerhetskultur och sjösäkerhet, Report no 27, Växjö University, Sweden, 2006. [ISM- code of safety organisation, safety culture and safety at sea]

[4] M. Blomé, Visualization of guidelines on computer networks to support processes of design and quality control, Ph.D. Dissertation, Lund University, 2004.

[5] M. Blomé, C. R. Johansson and P. Odenrick, Visualization of ergonomic guidelines - A comparison of two computer aided systems to support vehicle design, International journal of Industrial Ergonomics 36 (2006), 571-580.

[6] M. Blomé, C.R. Johansson and P. Odenrick, Computer supported visualisation of quality systems developed by network teams, Applied Ergonomics, 34 (3) (2003), 239-247. 